\title{
Is Change in Electrical Potential or pH a Hatching Signal for Heterodera glycines?
}

\author{
S. M. Pike, R. Heinz, T. Walk, C. Jones, G. A. Kraus, W. Gassmann, A. J. Novacky, and T. L. Niblack
}

First, second, sixth, and seventh authors: Department of Plant Microbiology and Pathology, University of Missouri, Columbia 65211; third author: Plant Physiology, Pennsylvania State University, University Park 16802; fourth and fifth authors: Department of Chemistry, Iowa State University, Ames 50011; and eighth author: Department of Crop Science, University of Illinois, Urbana 61801. Accepted for publication 12 December 2001 .

\section{ABSTRACT}

Pike, S. M., Heinz, R., Walk, T., Jones, C., Kraus, G. A., Gassmann, W., Novacky, A. J., and Niblack, T. L. 2002. Is change in electrical potential or $\mathrm{pH}$ a hatching signal for Heterodera glycines? Phytopathology 92:456463.

This study explored the possibilities that changes in the egg shell/lipid layer electrical potential or $\mathrm{pH}$ communicate external hatching conditions to the Heterodera glycines second-stage juvenile (J2) within the mature egg and that electrophysiology could measure effects of chemicals on emergence. Potentials were measured following application of the emergence inducers $\left(\mathrm{ZnSO}_{4}\right.$ and $\left.\mathrm{ZnCl}_{2}\right)$, ions that do not affect emergence, or synthetic emergence inhibitors. Results were compared with $\mathrm{pH}$ measurements and emergence bioassays. Healthy appearing eggs had negative resting potentials. Application of $\mathrm{ZnSO}_{4}$ caused a smooth depolarization.

Dormancy permits Heterodera glycines Ichinohe, soybean cyst nematode, to adapt to new environments and to survive for long periods of time within eggs when soybean plants are unavailable. A relatively large proportion of $H$. glycines eggs is in hostmediated dormancy (32). These eggs can escape an important control strategy, crop rotation, because they emerge only when a host is present. Consequently, researchers have sought ways to increase or reduce cyst nematode emergence in the absence of a host plant.

Many compounds affect the percentage of cyst nematode emergence, conventionally termed hatching, although induced emergence and hatching may not be identical processes. Millimolar concentrations of zinc consistently increased the emergence of $H$. glycines in laboratory experiments $(8,27,30)$. Reported plantderived hatch inducers are root exudate (29) and glycinoeclepin A (16), a compound isolated from kidney beans.

The effects of such compounds on $H$. glycines emergence are complex. Zinc fertilizers, although active in experiments in vitro, had no effect on nematode emergence when applied to the soil in greenhouse or field experiments (5). Some synthetic partial structures of glycinoeclepin A proved to be inhibitors rather than inducers of emergence $(13,14)$. A chitinase isolated from soybeans inhibited zinc-increased emergence in laboratory experiments (A. Smith, University of Missouri, unpublished data). The effect of $\mathrm{pH}$ on emergence showed a bell-shaped dose-response curve with optimum stimulation at $\mathrm{pH} 5.3$ (27). Environmental conditions also affected the hatch of $H$. glycines (32).

Researchers have hypothesized that compounds affecting nematode emergence act directly on the egg shell or are involved in

Corresponding author: S. M. Pike; E-mail address: pikes@missouri.edu

Publication no. P-2002-0301-01R

(C) 2002 The American Phytopathological Society
However, eggs containing $\mathrm{J} 2$ and immature eggs depolarized to a similar degree when $\mathrm{ZnSO}_{4}$ was added. In addition, $\mathrm{ZnSO}_{4}$, synthetic emergence inhibitors, and $\mathrm{CaCl}_{2}$ caused similar depolarization, and some depolarization was measured in dye-permeable eggs and empty shells. Results suggest that change in cation surface charge contributed to depolarization and that $\mathrm{Cl}^{-}$penetrated the egg shell/lipid layer without causing potential changes. In bioassays, zinc consistently stimulated emergence to a greater degree than $\mathrm{H}_{2} \mathrm{O}$, other cations, or buffers, and counteracted emergence inhibitors. Zinc-caused emergence stimulation was independent of $\mathrm{pH}$. In summary, it is concluded that depolarization and $\mathrm{pH}$ are not emergence signals and electrophysiology is unlikely to measure effectiveness of emergence stimulators or inhibitors.

Additional keywords: cyst nematode, soybean.

transmitting a signal across the shell to the nematode that the external environment is favorable for survival. For example, Clark and Perry (7) suggested that hatching agents may displace or bind to membrane-bound calcium and induce structural changes in the egg shell that increases its permeability. They measured changed calcium levels in shells of Globodera rostochiensis eggs following treatment with potato root exudates and zinc solutions (7). Other authors suggested that a calcium signaling cascade may mediate the hatching of cyst nematodes because calcium uptake increased (2), cyclic AMP increased (3), and phosphoinositide metabolism changed (1) after $G$. rostochiensis was exposed to potato root exudate. Although externally applied calcium had no effect in emergence experiments with $H$. glycines $(8,27)$, this fact alone does not rule out internal calcium-mediated signaling, because calcium can be mobilized from internal stores in response to external signals. However, a phospholipid membrane barrier containing proteinaceous receptors, channels, and/or transporters would be required for signaling.

The nematode egg shell is not well characterized; however, reported characteristics suggest that the innermost layer, the lipid layer, could be such a membrane. The lipid layer is considered to be the main permeability barrier of nematode egg shells to dyes (6). Histochemical tests of G. rostochiensis egg shells were positive for lipid, phospholipid, and protein in the lipid layer (20). Multiple membranes have been seen in the inner lipid layers of $H$. glycines (19) and G. rostochiensis (20) in electron micrographs. In our preliminary electron micrographs, the lipid layer membrane of H. glycines appeared to be a single bilayer membrane (T. Walk, unpublished data).

In biological organisms, the phospholipid bilayer allows cells to exclude or admit substances by diffusion or energy-dependent mechanisms. The end result is a charge differential, the electrical potential, that can be measured with glass microelectrodes. Electrical potentials of cells change in response to external stimuli 
such as nutrients, $\mathrm{pH}$, heat, light, wounding, and touch (12). If the $H$. glycines second-stage juvenile (J2) inside the mature egg senses external hatching conditions via a complex signaling system, we would expect to measure (i) distinct and different patterns of electrical potential change when emergence inducers or emergence inhibitors are applied externally to mature eggs, (ii) different changes or no changes in potentials of immature, early embryonic stages of eggs in response to these treatments, (iii) little or no potential in eggs that are permeable to dye, and (iv) effects of $\mathrm{pH}$ on potential changes.

Electrophysiology has been used as a tool in diverse studies ranging from the nervous system and physiology of insects to the characterization of nutrient transport and defense responses in plants. With plant parasitic nematodes, it only has been used to study the response of intact nematodes to stimulants (22) and pheromones (21-23), chemosensory responses of fourth-stage juveniles (24), and activity of $\mathbf{J} 2$ during recovery from desiccation (31). To our knowledge, it has not been used to study nematode eggs.

We investigated the electrophysiological response of the egg shell/lipid layer to known inducers or inhibitors of emergence and compared the results to $\mathrm{pH}$ measurements and emergence assays. Our goals were to determine (i) whether patterns of change in electrical potential or $\mathrm{pH}$ could be signals that $H$. glycines uses to sense the external environment, and (ii) whether electrophysiology could be used to measure the effectiveness of chemicals as stimuli or inhibitors of emergence. We found that electrical potential changes were not correlated with emergence and that electrophysiology did not measure the effectiveness of chemical stimuli or inhibitors of emergence. Surprisingly, our results suggested that intact egg shells may be permeable to anions and that zinc affected emergence independently of $\mathrm{pH}$.

\section{MATERIALS AND METHODS}

Culturing $\boldsymbol{H}$. glycines. An isolate of $H$. glycines designated TN1 (race phenotype 5) was maintained as a greenhouse culture in sterilized field sand ( $74 \%$ sand, $16 \%$ silt, and $10 \%$ clay) on soybean, Glycine $\max$ cv. Essex, in water tables at $27^{\circ} \mathrm{C}$. Eggs were extracted from 29- to 35-day-old cultures. This isolate was used for all emergence experiments, all electrophysiological experiments involving emergence inhibitors or dye-permeable eggs, for split-chamber tests, and for 23 of 27 experiments to determine the averaged maximum 30-min egg shell/lipid layer depolarization caused by $15 \mathrm{mM} \mathrm{ZnSO}_{4}$. Field populations were included in other electrophysiological measurements.

Extraction. Mature females and cysts were extracted from sand and roots by sieving (4). Eggs were extracted from cysts by a mechanical method (17) and were suspended in $\mathrm{H}_{2} \mathrm{O}$. Hibitane (chlorhexidine) was added at $0.1 \%$ to minimize contamination and microbial effects without affecting emergence (30). After $10 \mathrm{~min}$, eggs were rinsed and resuspended in sterile deionized $\mathrm{H}_{2} \mathrm{O}$. Egg suspensions were kept mixed by air bubbled into the suspension. Initial $H$. glycines egg concentrations were estimated by the aliquot method (9).

Emergence bioassay. Each bioassay unit (30) consisted of a $30-\mu \mathrm{m}$ pore nylon mesh (Nitex 7-30/20) held between two 50-ml Tri-Pour disposable plastic beakers (Sherwood Medical Industries, St. Louis). These beakers, cut off either between the $25 \mathrm{ml}$ marks for the top or the $40 \mathrm{ml}$ marks for the bottom, were set in the bottom half of a sterile petri dish $(60 \times 15 \mathrm{~mm})$ with mesh approximately $3 \mathrm{~cm}$ off the bottom of the dish. Mesh and cut-off beakers were thoroughly washed, soaked in $10 \%$ sodium hypochlorite, assembled, and autoclaved before each experiment.

For bioassays, $1 \mathrm{ml}$ of $H$. glycines-egg suspensions containing an estimated 1,000 eggs was placed on the mesh in petri dishes. Additional $\mathrm{H}_{2} \mathrm{O}$ (approximately $2 \mathrm{ml}$ ) was added to bring the mesh in contact with the $\mathrm{H}_{2} \mathrm{O}$. After $24 \mathrm{~h}$, the water and hatched $\mathrm{J} 2$ were discarded and approximately $3 \mathrm{ml}$ of treatment solution was added. Each treatment was replicated five times and repeated at least once. The mesh in each bioassay unit remained in contact with liquid throughout the experiment. Bioassay units were stacked on porcelain or plastic plates in an airtight chamber, to which water was added to maintain high humidity. These humid chambers were stored at room temperature $\left(23\right.$ to $\left.26^{\circ} \mathrm{C}\right)$, because in a preliminary experiment, we found that zinc increased emergence significantly at room temperature but not in an incubator at $27^{\circ} \mathrm{C}$.

Emerged $\mathrm{J} 2$ that passed through the mesh and remaining eggs were counted at the end of 2 weeks. Three to four drops of acid fuchsin egg stain (4) was added to each counting dish and the contents were microwaved to the boiling point. Material on bioassay sieves was rinsed into counting dishes. Eggs remaining on the sieve mesh were counted. Stained J2 and unhatched eggs were counted. The percent that hatched was calculated as $[\mathrm{J} 2 /(\mathrm{J} 2+$ eggs)] $\times 100$.

Chemicals. Reagent grade or higher chemicals from Sigma Chemical Co. (St. Louis) and Fisher Scientific (Houston, TX) were used. One molar stocks of $\mathrm{CaCl}_{2}, \mathrm{LiCl}, \mathrm{ZnCl}_{2}, \mathrm{ZnSO}_{4}, N-(2-$ hydroxyethyl)piperazine- $N^{\prime}$-(2-ethanesulfonic acid) (HEPES), $\mathrm{pH}$ 7.02, and 2-( $N$-morpholino)ethanesulfonic acid (MES), pH 6.72, were prepared and were used at a final concentration of $15 \mathrm{mM}$. Thirty-three millimolar $\mathrm{HCl}$, the concentration used to dissolve $\mathrm{ZnCl}_{2}$, used at a final concentration of $0.5 \mathrm{mM}$, or sterile double deionized $\mathrm{H}_{2} \mathrm{O}$ were control solutions for these additions. A Corning pH meter 240 (Corning Inc., Acton, MA) was used to measure solution $\mathrm{pH}$.

2-Hydroxymethylenecyclopentanone (Aa) was synthesized from cyclopentanone (1 eq), ethyl formate (1.1 eq), and potassium tert-butoxide $(1.1 \mathrm{eq})$ in tetrahydrofuran $(\mathrm{THF})$ at $0^{\circ} \mathrm{C}$. The cyclopentanone/ethyl formate mixture was added dropwise to the THF solution at $0^{\circ} \mathrm{C}$. Flash chromatography on silica gel, eluting with $n$-hexane/ethyl acetate (4:1), gave a $96 \%$ yield of the ketoaldehyde. Alpha, 2-dioxo cyclopentaneacetic acid, ethyl ester (Va), was synthesized from cyclopentanone (1 eq), diethyl oxalate (1.1 eq), and potassium tert-butoxide $(1.1 \mathrm{eq})$ in THF at $0^{\circ} \mathrm{C}$. The cyclopentanone/diethyl oxalate mixture was added dropwise to the THF solution at $0^{\circ} \mathrm{C}$. Flash chromatography on silica gel, eluting with $n$-hexane/ethyl acetate (4:1), gave an $84 \%$ yield of the ketoester. Aa and Va were dissolved in ethanol and added to $\mathrm{H}_{2} \mathrm{O}$, final concentration $100 \mathrm{ppm}$, a concentration previously shown to reduce emergence (28).

A sterile preparation of chitinase isoforms from soybean seeds was provided by A. Smith (University of Missouri). Soybean chitinase was used at a final concentration of 1 unit per $\mathrm{ml}$, a concentration that was previously shown to reduce emergence in $30 \mathrm{mM}$ zinc solutions by one-third to one-half (A. Smith, unpublished data).

Electrophysiological setup. During measurements, individual eggs were immobilized in the necks of microfunnels (Fig. 1). Microfunnels were produced from 1-mm-diameter glass capillaries (World Precision Instruments, Sarasota, FL) with a microforge as described previously (25). The funnel cups were further opened by partially breaking them against the heating coil.

Microelectrodes consisted of fiberglass-filament-containing 1.0-mm-diameter borosilicate glass capillaries that were pulled to a tip diameter of $0.5 \mu \mathrm{m}$ with a vertical puller (D. Kopf, Tujunga, $\mathrm{CA}$ ) and filled with $3 \mathrm{M} \mathrm{KCl}$. Tip potentials of 10 measuring electrodes in $10 \mathrm{ml}$ of $\mathrm{H}_{2} \mathrm{O}$ containing $20 \mu \mathrm{l}$ of egg suspension averaged $-7 \pm 4 \mathrm{mV}$, with a resistance of $19 \pm 2 \mathrm{M} \Omega$. Reference electrodes were 2.0-mm-diameter polyethylene tubes containing $3 \mathrm{M} \mathrm{KCl}$ in $2 \%$ agar. Microelectrodes and reference electrodes were connected to an electrometer amplifier (Intra 767; World Precision Instruments) with $\mathrm{Ag} / \mathrm{AgCl}$ wires. Narishige (Narishige Scientific Instrument Laboratory, Tokyo, Japan) hydraulic microdrives mounted to Leitz (Ernst Leitz Wetzlar, Wetzlar, Germany) 
micromanipulators were used to position the microfunnel and microelectrode in the field of an inverted microscope (IMT-2; Olympus Corporation, Melville, NY).

Electrophysiological measurements of nematode eggs. For electrophysiological experiments with mature and immature eggs, eggs in sterile double-deionized $\mathrm{H}_{2} \mathrm{O}$ were air bubbled at $4^{\circ} \mathrm{C}$ and were used 24 to $56 \mathrm{~h}$ after extraction. For electrophysiological measurements of eggs with permeabilized lipid layers, $1 \mathrm{ml}$ of acid fuchsin dye (4) was added to approximately $40 \mathrm{ml}$ of egg suspension. Half the egg/dye mixture was microwaved just to boiling. Eggs were stored at $4^{\circ} \mathrm{C}$ overnight in dye without air bubbling. The eggs were rinsed with $4 \mathrm{ml}$ of sterile double-

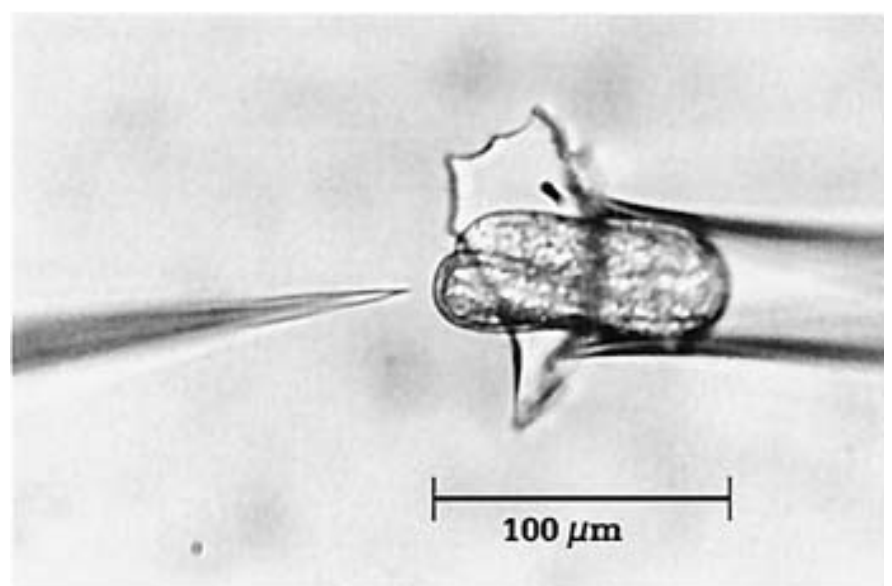

Fig. 1. Microelectrode (left) and microfunnel holding a typical mature egg that contains a second-stage juvenile (right) prior to electrophysiological measurement.

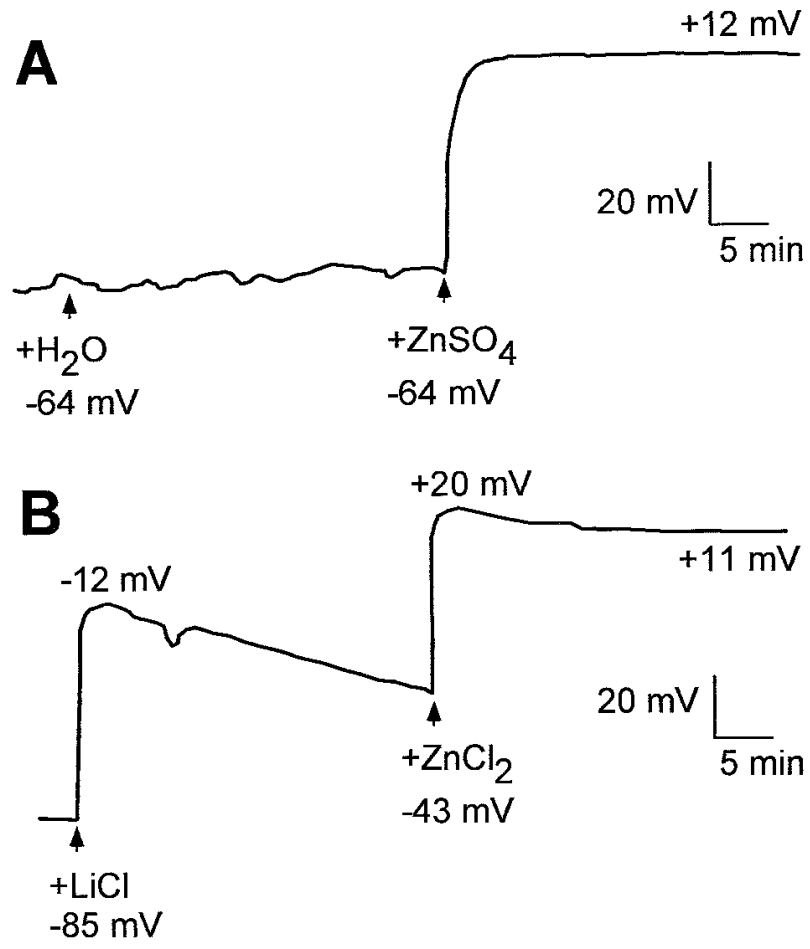

Fig. 2. Electrophysiological tracings of mature egg shell/lipid layer response to added $\mathrm{H}_{2} \mathrm{O}$ or ion stock solutions (final concentration $15 \mathrm{mM}$ ). Measurements were initiated in $\mathrm{H}_{2} \mathrm{O}$. At the first arrow, $150 \mu \mathrm{l}$ of stock solution or $\mathrm{H}_{2} \mathrm{O}$ was pipetted into the chamber as indicated. Approximately 30 min later, a different stock solution was added at the second arrow. Numerical values in millivolts $(\mathrm{mV})$ are the potential before treatment, maximum depolarized potential, and the potential $30 \mathrm{~min}$ after addition. deionized $\mathrm{H}_{2} \mathrm{O}$ and sedimented. The rinse water was replaced with sterile double-deionized $\mathrm{H}_{2} \mathrm{O}$.

Measurements were performed at room temperature and were initiated in double-deionized $\mathrm{H}_{2} \mathrm{O}$. A 20 - $\mu$ l drop of egg suspension containing 500 to 1,000 eggs was pipetted into the $\mathrm{H}_{2} \mathrm{O}$ and sedimented at the center of the coverslip bottom of a 10-ml Plexiglas $(55 \times 38 \times 12 \mathrm{~mm})$ measuring chamber. An egg was captured by suction from the coverslip bottom. Eggs containing a nematode with a visible stylet or with a shell that was deformed to fit the nematode were selected for measurements of mature eggs. Darkcolored eggs containing many cells were selected for measurements of immature eggs. Eggs with permeable lipid layers were stained dark red. The protruding end of the immobilized egg was impaled with the measuring electrode. When the measurement was stable for at least $2 \mathrm{~min}, 150 \mu \mathrm{l}$ of treatment stock solution or $\mathrm{H}_{2} \mathrm{O}$ was pipetted at the edge of the chamber, approximately $2 \mathrm{~cm}$ from the egg and $4 \mathrm{~cm}$ from the reference electrode. Thirty minutes later, the experiment was terminated or another treatment solution was pipetted into the chamber. As another control, microelectrodes were removed just outside the egg immediately after impalement and stock solutions were applied. At least three to four measurements of each type were performed. Results are expressed as averages $\pm \mathrm{SD}$.

Split-chamber control for electrophysiological measurements. The split-chamber system consisted of two plastic petri dishes $(55 \times 13 \mathrm{~mm})$ connected by a bent water-filled $1.5-\mathrm{mm}$ diameter glass capillary. Measuring and reference electrodes occupied positions in the separate chambers analogous to their positions and depth in the Plexiglas measuring chamber. Egg suspension was added to the center of each chamber. In the measuring chamber, eggs were immobilized in the microfunnel. After a stable potential was recorded for $2 \mathrm{~min}, 150 \mu \mathrm{l}$ of $1 \mathrm{M}$ $\mathrm{ZnCl}_{2}$ or $\mathrm{ZnSO}_{4}$ stock was pipetted at the edge of one chamber and the potential change was recorded for $30 \mathrm{~min}$.

Statistical methods used for hatching assays. Percentage of hatching was analyzed using the general linear models (GLM) procedure of SAS software (SAS Institute, Cary, NC). Means of percentage of hatching for each treatment were separated with the Waller-Duncan $k$ ratio $t$ test.

\section{RESULTS}

Impalement and resting potentials. Upon impaling an intact egg, we measured a 20 to $30 \mathrm{mV}$ negative potential when the electrode tip penetrated the outer egg shell. When the electrode was pushed further into the egg, the shell typically invaginated slightly, producing an unstable, very negative potential. Further pressure resulted in a positive potential and then a negative potential that stabilized in the range of -30 to $-130 \mathrm{mV}$, the resting

TABLE 1. Shell/lipid layer depolarization measured when ions were added to the Plexiglas measuring chamber after egg impalement ${ }^{\mathrm{a}}$

\begin{tabular}{llc}
\hline & \multicolumn{2}{c}{$\Delta \mathrm{E}_{\mathrm{m}}(\mathrm{mV} \pm \mathrm{SD})^{\mathrm{b}}$} \\
\cline { 2 - 3 } Ion addition & \multicolumn{1}{c}{$5 \mathrm{mM}$} & $15 \mathrm{mM}$ \\
\hline $\mathrm{ZnSO}_{4}$ & $+80 \pm 14(5)$ & $+70 \pm 16(27)$ \\
$\mathrm{ZnCl}_{2}$ & $+75 \pm 9(4)$ & $+86 \pm 17(9)$ \\
$\mathrm{CaCl}_{2}$ & $+65 \pm 21(4)$ & $+72 \pm 19(13)$ \\
$\mathrm{MgCl}_{2}$ & $+71 \pm 19(5)$ & $\mathrm{ND}$ \\
$\mathrm{LiCl}$ & $+28 \pm 11(4)$ & $+43 \pm 12(8)$ \\
$\mathrm{NaCl}_{\mathrm{Na}}$ & $+33 \pm 17(4)$ & $\mathrm{ND}$ \\
- & $+56 \pm 17(4)$ & $\mathrm{ND}$
\end{tabular}

a Measuring and reference electrodes were submerged in a Plexiglas chamber containing $\mathrm{H}_{2} \mathrm{O}$. The immobilized egg was impaled with the measuring electrode. Two minutes after a stable potential was recorded, ion stock was pipetted at the edge of the chamber and the potential change was recorded.

${ }^{\mathrm{b}}$ Each $\Delta \mathrm{E}_{\mathrm{m}}$, calculated as (millivolt potential after $30 \mathrm{~min}$ ) - (millivolt initial potential), is the mean of $n$ measurements shown in parentheses, $\pm \mathrm{SD}$, at final concentrations of 5 and $15 \mathrm{mM}$. $\mathrm{ND}=$ not done. 
potential. In some of these measurements, leaked granules or droplets indicated that this final negative potential occurred when the membrane or nematode had been punctured. It was not possible to determine if the tip of the electrode touched or punctured the nematode. Mature eggs that appeared swollen or ones that had moving nematodes were not selected for measurement. However, the nematode sometimes moved after the egg was impaled and occasionally pushed the electrode out of the egg, terminating the measurement.

Effect of ion solutions on electrical potential. When a mature egg was impaled, the pipetted addition of 5 to $15 \mathrm{mM}$ ions resulted in a smooth large depolarization (i.e., more positive potential) (Fig. 2A and B) in contrast to the spikes reported for intact active nematodes (18). The potential usually repolarized at least a few millivolts within $30 \mathrm{~min}$ (Fig. 2B). Table 1 shows the average depolarization $30 \mathrm{~min}$ after the addition of $\mathrm{ZnSO}_{4}, \mathrm{ZnCl}_{2}, \mathrm{CaCl}_{2}$, $\mathrm{MgCl}_{2}, \mathrm{LiCl}, \mathrm{NaCl}$, or $\mathrm{Na}_{2} \mathrm{SO}_{4}$. In control treatments, a much smaller depolarization was measured following addition of $\mathrm{H}_{2} \mathrm{O}$, $5 \pm 14 \mathrm{mV}$ (Fig. 2A), or when the electrode was removed from the egg and $\mathrm{ZnSO}_{4}$ was added to the chamber, $1.5 \pm 2.5 \mathrm{mV}$.

The magnitude of average depolarization was similar for divalent cations expected to stimulate emergence $\left(\mathrm{ZnSO}_{4}\right.$ and $\left.\mathrm{ZnCl}_{2}\right)$ as well as those expected to have little effect $\left(\mathrm{CaCl}_{2}\right)$ or to decrease emergence $\left(\mathrm{MgCl}_{2}\right)$ (Table 1). The fact that 5 and $15 \mathrm{mM}$ final concentrations caused similar amounts of depolarization suggested that $5 \mathrm{mM}$ divalent cation may produce maximum values. A range of $\mathrm{ZnSO}_{4}$ concentrations was tested, and $5 \mathrm{mM}$ caused maximum depolarization (Fig. 3). Because $15 \mathrm{mM} \mathrm{ZnSO}_{4}$ was previously found to be necessary for a consistent increase in emergence (30), $15 \mathrm{mM}$ was chosen as the concentration to further investigate the effect of ions on depolarization, $\mathrm{pH}$, and emergence.

Monovalent cations had much less effect than divalent cations on the potentials of mature eggs. Thirty minutes after addition, $\mathrm{LiCl}$ and $\mathrm{NaCl}$ produced about half the depolarization caused by divalent cations (Table 1). This difference was partly caused by the greater repolarization observed $30 \mathrm{~min}$ after addition of monovalent cations (Fig. 2B). Five millimolar monovalent cation did not cause maximum depolarization; for example, compare $5 \mathrm{mM}$ $\mathrm{LiCl}$ to $15 \mathrm{mM} \mathrm{LiCl}$ and $5 \mathrm{mM} \mathrm{NaCl}$ to $5 \mathrm{mM} \mathrm{Na}_{2} \mathrm{SO}_{4}$ (Table 1). Furthermore, at final concentrations of $15 \mathrm{mM}, \mathrm{ZnCl}_{2}$ caused an additional depolarization of $51 \pm 22 \mathrm{mV}$ when added 30 min after $\mathrm{LiCl}$ (Fig. 2B), but $\mathrm{ZnCl}_{2}$ added after $\mathrm{CaCl}_{2}$ caused only 10 to $20 \mathrm{mV}$ additional depolarization (data not shown).

The addition of $\mathrm{HCl}$, final $\mathrm{pH} 3.4$, caused a surprising $109 \pm$ $29 \mathrm{mV}$ depolarization when added to the bath solution at a final

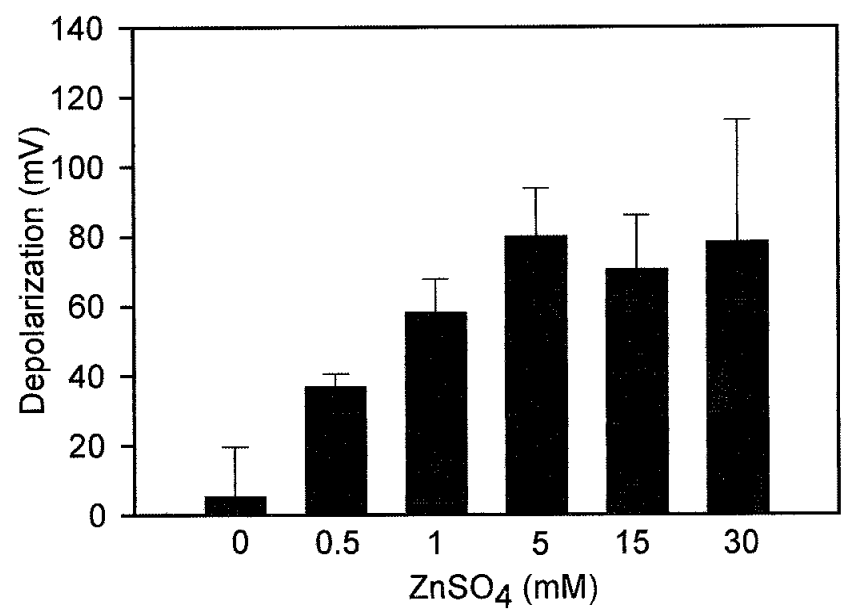

Fig. 3. Average depolarization of mature egg shell/lipid layer $30 \mathrm{~min}$ after addition of $\mathrm{ZnSO}_{4}$ ( 0 to $30 \mathrm{mM}$ final concentration). Bars are means of four to seven measurements $\pm \mathrm{SD}$ with the exception of $15 \mathrm{mM} \mathrm{ZnSO} 4$ $(n=27)$. concentration of only $0.5 \mathrm{mM}$. This value is comparable to that for $15 \mathrm{mM} \mathrm{ZnCl}{ }_{2}$ containing $0.5 \mathrm{mM} \mathrm{HCl}$, or $\mathrm{ZnSO}_{4}$ containing no $\mathrm{HCl}$ (Table 1). When the electrode was removed from the egg prior to the addition, $0.5 \mathrm{mM} \mathrm{HCl}$ caused only a few millivolts depolarization (data not shown). These results suggest that protons have an independent maximum effect on the shell/lipid layer potential.

Split chamber control for electrophysiological measurements. Ionic current in solution is converted into electron current in the $\mathrm{Ag}$ wires coated with $\mathrm{AgCl}$. The slight difference in ion mobility in the $3 \mathrm{M} \mathrm{KCl}$ measuring electrode and the $3 \mathrm{M} \mathrm{KCl}$ agar electrode was zeroed electronically. However, when the bath concentration of ions is greatly changed, as from $\mathrm{H}_{2} \mathrm{O}$ containing $20 \mu \mathrm{l}$ of egg suspension to $15 \mathrm{mM}$ ion solution, an offset may develop, perhaps because the geometries of the reference and measuring electrodes differ or because the electrodes may not be equally accessible to ions. Drastically changing the chloride concentration may in particular present a problem resulting from its impact on the liquid junction potential between bathing solution and the salt bridge $\mathrm{KCl}$ solution. For these reasons, we measured electrode potential changes in a split-chamber analogous system in which electrodes were in separate chambers electrically connected by a water-filled bridge. Eggs were not impaled. Table 2 shows the average depolarization (more positive potentials) or hyperpolarization (more negative potentials) measured 30 min after $\mathrm{ZnCl}_{2}$ or $\mathrm{ZnSO}_{4}$ was added to only one of these chambers.

A potential change occurred when $\mathrm{ZnSO}_{4}$ or $\mathrm{ZnCl}_{2}$ was added to either the reference chamber or the measuring chamber. When the same ion stock was added, the magnitude of potential change in the measuring chamber $\left(\Delta \mathrm{E}_{\mathrm{mc}}\right)$ was approximately equal but opposite in polarity to that in the reference chamber $\left(\Delta \mathrm{E}_{\mathrm{rc}}\right)$ (Table 2 ). The total offset error, $\Delta \mathrm{E}_{\mathrm{mc}}+\Delta \mathrm{E}_{\mathrm{rc}}$, was a small depolarization showing that little offset develops even from $30 \mathrm{mM}$ added chloride $\left(\Delta \mathrm{E}_{\text {tot }}\right)$ (Table 2$)$.

Comparison of potential changes of eggs in the Plexiglas chamber (Table 1) and those of electrodes in the split chamber (Table 2) following $\mathrm{ZnSO}_{4}$ and $\mathrm{ZnCl}_{2}$ addition showed that the measuring electrode responded to $\mathrm{Cl}^{-}$concentration change as effectively when it was inside the egg as it did when in contact with bath solution. In the split-chamber measurements, both electrodes measured much greater change in potential from added $\mathrm{ZnCl}_{2}$ than added $\mathrm{ZnSO}_{4}$ (Table 2, $\Delta \mathrm{E}_{\mathrm{mc}}, \Delta \mathrm{E}_{\mathrm{rc}}$ ). Thus, if only the reference electrode were accessible to anions in the Plexiglas chamber, added $\mathrm{Cl}^{-}$should have caused approximately $50 \mathrm{mV}$ less total depolarization than added $\mathrm{SO}_{4}{ }^{2-}$. However, in the Plexiglas

TABLE 2. Depolarization or hyperpolarization measured when $\mathrm{ZnSO}_{4}$ or $\mathrm{ZnCl}_{2}$ was added to either the measuring or reference chamber of a splitchamber system without egg impalement ${ }^{\mathrm{a}}$

\begin{tabular}{lccc}
\hline & \multicolumn{3}{c}{$\mathrm{mV} \pm \mathrm{SD}$} \\
\cline { 2 - 4 } Ion addition $^{\mathrm{b}}$ & $\Delta \mathrm{E}_{\mathrm{mc}}{ }^{\mathrm{c}}$ & $\Delta \mathrm{E}_{\mathrm{rc}}{ }^{\mathrm{d}}$ & $\Delta \mathrm{E}_{\mathrm{tot}}{ }^{\mathrm{e}}$ \\
\hline $\mathrm{ZnSO}_{4}$ & $+18 \pm 8$ & $-9 \pm 5$ & $+9 \pm 9$ \\
$\mathrm{ZnCl}_{2}$ & $+75 \pm 1$ & $-62 \pm 15$ & $+13 \pm 15$ \\
\hline
\end{tabular}

${ }^{a}$ Measuring and reference electrodes were each submerged in a separate petri dish chamber, and the chambers were connected to each other by a bent $\mathrm{H}_{2} \mathrm{O}$-filled glass tube. After a stable potential was recorded, the indicated ion stock was added at the edge of either measuring or reference chamber and the potential change was recorded.

$\mathrm{b}$ Final concentration $=15 \mathrm{mM}$.

${ }^{c} \Delta \mathrm{E}_{\mathrm{mc}}$ denotes the change in potential following ion addition to the measuring chamber. $\Delta \mathrm{E}_{\mathrm{mc}}$ is calculated as (millivolt potential $30 \mathrm{~min}$ after ion addition) - (millivolt potential prior to addition). Values shown are means of three experiments $\pm \mathrm{SD}$.

${ }^{\mathrm{d}} \Delta \mathrm{E}_{\mathrm{rc}}$ denotes the change in potential following ion addition to the reference chamber. $\Delta \mathrm{E}_{\mathrm{rc}}$ is calculated as (millivolt potential $30 \mathrm{~min}$ after ion addition) (millivolt potential prior to addition). Values shown are means of three experiments $\pm \mathrm{SD}$.

e $\Delta \mathrm{E}_{\mathrm{tot}}=\Delta \mathrm{E}_{\mathrm{mc}}+\Delta \mathrm{E}_{\mathrm{rc}}$. 
chamber egg shell/lipid layer measurements, $\mathrm{ZnSO}_{4}$ and $\mathrm{ZnCl}_{2}$ additions both produced approximately $+80 \mathrm{mV}$ changes in potential (Table 1). This can be explained if measuring and reference electrodes were equally accessible to anions during measurements of eggs in the Plexiglas chamber and their opposite polarities canceled anion contribution to the potential as in the split-chamber $\Delta \mathrm{E}_{\mathrm{tot}}$. Then $\mathrm{Zn}^{2+}$ addition would produce similar depolarizations with either $\mathrm{ZnCl}_{2}$ or $\mathrm{ZnSO}_{4}$. Thus, changes of potential measured in the Plexiglas chamber are associated with the egg rather than an artifact caused by change in the reference electrode junction potential.

Effect of ion solutions on $\mathbf{p H}$ and emergence. In all emergence assays, $\mathrm{ZnCl}_{2}$ or $\mathrm{ZnSO}_{4}$ consistently caused greater emergence than the $\mathrm{H}_{2} \mathrm{O}$ control, $\mathrm{LiCl}$, or $\mathrm{CaCl}_{2}$ (Fig. 4). The addition of either $\mathrm{ZnCl}_{2}$ or $\mathrm{ZnSO}_{4}$ to $\mathrm{LiCl}$ or $\mathrm{CaCl}_{2}$ solutions consistently increased emergence to values equal to that caused by zinc solutions alone. $\mathrm{CaCl}_{2}$ and the $\mathrm{H}_{2} \mathrm{O}$ control consistently caused equal emergence. $\mathrm{LiCl}$ caused emergence equal to $\mathrm{H}_{2} \mathrm{O}$ (Fig. 4) or was slightly more effective than $\mathrm{H}_{2} \mathrm{O}$ (data not shown).

Emergence triggered by ions was related to $\mathrm{pH}$ as was previously reported by Tefft and Bone (27). The $\mathrm{pH}$ of $\mathrm{H}_{2} \mathrm{O}$ measured 6.3. From acidic to basic, $\mathrm{pH}$ of the $15 \mathrm{mM}$ ion solutions was in the following order: $\mathrm{ZnCl}_{2}(5.0)<\mathrm{ZnSO}_{4}(5.6)<\mathrm{CaCl}_{2}(6.5)<$ $\mathrm{LiCl}$ (7.2). The addition of $\mathrm{ZnCl}_{2}$ to $\mathrm{LiCl}$ or $\mathrm{CaCl}_{2}$ solutions reduced the $\mathrm{pH}$ to 4.8 and 4.9 , respectively (values similar to that of $\mathrm{ZnCl}_{2}$ alone). $\mathrm{ZnSO}_{4}$ added to $\mathrm{CaCl}_{2}$ likewise dropped the $\mathrm{pH}$ to 5.2 (a value similar to that of $\mathrm{ZnSO}_{4}$ alone).

Effect of buffering on electrical potential, pH, and emergence. Because ion solutions with neutral $\mathrm{pH}$ had little or no effect on emergence in our experiments, we buffered $\mathrm{ZnSO}_{4}$ solutions to a more neutral $\mathrm{pH}$ with MES or HEPES at a final concentration of $15 \mathrm{mM}$. Before $\mathrm{ZnSO}_{4}$ was added, the final $\mathrm{pH}$ of MES and HEPES treatment solutions ranged from 6.3 to 6.6 and 6.4 to 6.8 , respectively. The addition of $15 \mathrm{mM} \mathrm{ZnSO}_{4}$ to the buffers caused little change in $\mathrm{pH}$, but precipitate formed.

In electrophysiological measurements of mature eggs, both MES and HEPES caused substantial depolarization themselves, (Fig. 5) perhaps as a result of their $\mathrm{K}^{+}$content of 12.8 and $3.7 \mathrm{mM}$, respectively. When $15 \mathrm{mM} \mathrm{ZnSO}_{4}$ was added to the chamber $30 \mathrm{~min}$ after either buffer, precipitate formed and we measured about half of the expected zinc-caused depolarization. Total depolarization, [(buffer-caused depolarization) $+\left(\mathrm{ZnSO}_{4}{ }^{-}\right.$ caused depolarization)], was about equal to depolarization caused

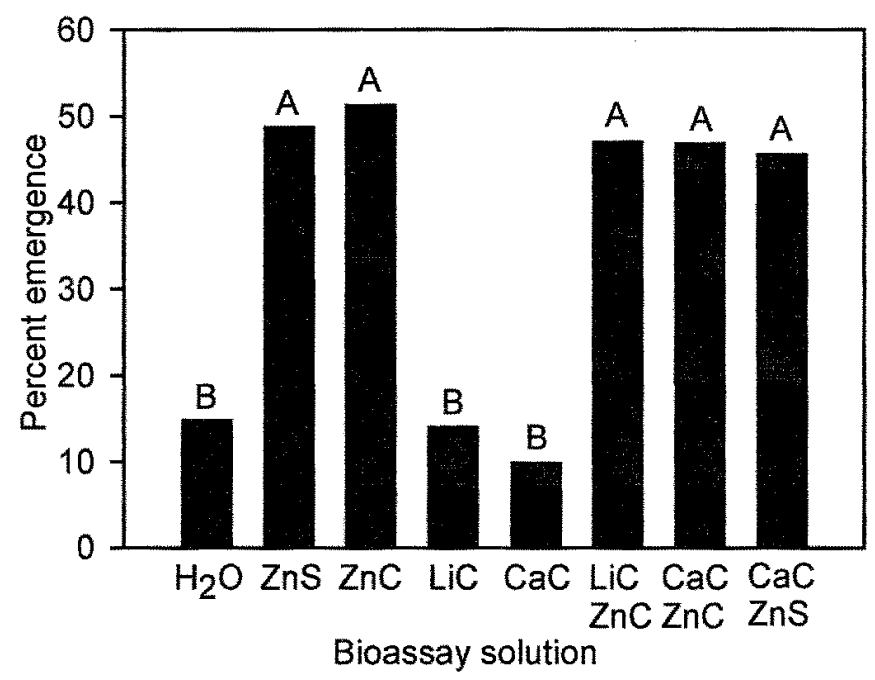

Fig. 4. Percent emergence after treatments with $\mathrm{H}_{2} \mathrm{O}, 15 \mathrm{mM} \mathrm{ZnSO}_{4}(\mathrm{ZnS})$, $\mathrm{ZnCl}_{2}(\mathrm{ZnC}), \mathrm{LiCl},(\mathrm{LiC}), \mathrm{CaCl}_{2}(\mathrm{CaC})$, or combinations of these ions as shown. Bars are means of five repetitions. Different letters above the bars denote significant differences $(P=0.0001)$. These differences were also significant in a second experiment. by $\mathrm{ZnSO}_{4}$ alone (Fig. 5). When $\mathrm{ZnSO}_{4}$ was applied first, HEPES caused little change in potential, suggesting that the maximum depolarization had been reached with $\mathrm{ZnSO}_{4}$ and could not be reduced by buffer. The effect of MES was similar but more variable.

In emergence assays, buffered $\mathrm{ZnSO}_{4}$ solutions were less effective in stimulating emergence than $\mathrm{ZnSO}_{4}$ in about half of the experiments (Fig. 6). HEPES alone and MES alone did not affect emergence compared with $\mathrm{H}_{2} \mathrm{O}$. Addition of $\mathrm{ZnSO}_{4}$ significantly increased emergence above that of the buffer alone except in one of the three experiments with MES in which MES- and $\mathrm{ZnSO}_{4}-$ caused emergence were not significantly different from each other.

Effect of inhibitors on electrical potential, pH, and hatching. We included the partial glycinoeclepin analogues, Aa and Va, and soybean chitinase in this study to see if these synthetic inhibitors of emergence similarly affect $\mathrm{pH}$ or electrical potential. Aa and Va were also included in emergence assays, but there was insufficient chitinase for the latter assay.

In electrophysiological measurements of mature eggs, $\mathrm{Aa}$ caused approximately $16 \mathrm{mV}$ more depolarization than $\mathrm{ZnSO}_{4}$. This small depolarization may be real because when Aa was added after $\mathrm{ZnSO}_{4}, 5$ to $16 \mathrm{mV}$ further depolarization was seen in three of five measurements, whereas when $\mathrm{ZnSO}_{4}$ was added after Aa, 8 to $15 \mathrm{mV}$ repolarization was seen in three of four measurements. Va was remarkably like Aa in amount of depolarization, pattern of depolarization when Va was added after $\mathrm{ZnSO}_{4}$, and repolarization when $\mathrm{ZnSO}_{4}$ was added after $\mathrm{Va}$ (data not shown).

As previously observed by Thompson and Tylka (28), Aa significantly inhibited emergence compared with $\mathrm{H}_{2} \mathrm{O}$ (Fig. 6). When $\mathrm{ZnSO}_{4}$ was added to $\mathrm{Aa}$, the inhibition was abolished and emergence consistently increased above that in $\mathrm{H}_{2} \mathrm{O}$, a significant difference in two of three experiments. However, compared with $\mathrm{ZnSO}_{4}$ alone, Aa reduced zinc-stimulated emergence. Aa solutions, $\mathrm{pH} 3.8$ to 4.0 , and $\mathrm{Va}, \mathrm{pH} 3.4$ to 3.7 , were approximately $2 \mathrm{pH}$ units more acidic than $\mathrm{ZnSO}_{4}$ and $\mathrm{pH}$ did not change with $\mathrm{ZnSO}_{4}$ addition. Results with autoclaved Aa were similar for

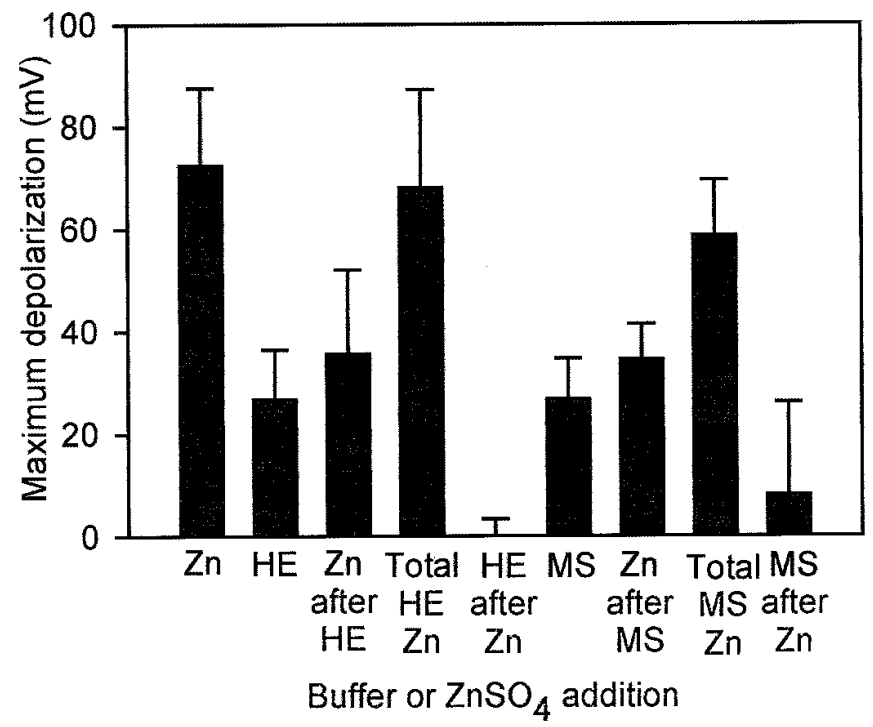

Fig. 5. Average maximum depolarization of the mature egg shell/lipid layer resulting from the addition of the biological buffers, $N$-2-hydroxyethylpiperazine- $N^{\prime}$-2-ethanesulfonic acid (HEPES [HE], final $\mathrm{pH} 6.4$ to 6.8), 2-( $N$ morpholino)ethanesulfonic acid (MES [MS], final $\mathrm{pH} 6.3$ to 6.6), or $\mathrm{ZnSO}_{4}$ $(\mathrm{Zn})$ at a final concentration of $15 \mathrm{mM}$. After $30 \mathrm{~min}, \mathrm{ZnSO}_{4}$ was added to buffer treatments or buffer was added to $\mathrm{ZnSO}_{4}$ treatments. For each twoaddition experiment, the total depolarization was computed as (buffer-caused depolarization $)+\left(\mathrm{ZnSO}_{4}\right.$-caused depolarization $)$. Bars are means of four to five experiments \pm SD. The averaged maximum depolarization from $15 \mathrm{mM}$ $\mathrm{ZnSO}_{4}(n=27)$ is shown for comparison. 
depolarization, $\mathrm{pH}$, and emergence (data not shown). Although the trends were in the same direction as seen with Aa, emergence caused by $\mathrm{Va}$ and $\mathrm{Va} / \mathrm{ZnSO}_{4}$ were not significantly different from $\mathrm{H}_{2} \mathrm{O}$ (data not shown).

The chitinase solution contained precipitate before addition of $\mathrm{ZnSO}_{4}$. The $\mathrm{pH}$ of the chitinase solution, 5.1, was a little more acidic than $\mathrm{ZnSO}_{4}$ and became slightly more acidic, 4.7, with added $\mathrm{ZnSO}_{4}$. Depolarization caused by chitinase addition averaged $55 \pm 11 \mathrm{mV}$. $\mathrm{ZnSO}_{4}$ added after chitinase produced 15 to $47 \mathrm{mV}$ more depolarization. Soybean chitinase was previously shown to reduce emergence triggered by $30 \mathrm{mM} \mathrm{ZnSO}_{4}$ (A. Smith, unpublished data)

Potential changes in eggs that cannot hatch. We expected the magnitude or pattern of depolarization to be different in eggs that could hatch and eggs that could not if the measured depolarization were an emergence signal. Potentials before treatment in early embryonic stages of eggs ranged from -49 to $-93 \mathrm{mV}$, similar to mature eggs. The pattern of depolarization was similar in both and the amount of depolarization $30 \mathrm{~min}$ after application of $15 \mathrm{mM}$ $\mathrm{ZnSO}_{4}$ was comparable in both: $+70 \pm 16 \mathrm{mV}$ in mature eggs and $+74 \pm 4 \mathrm{mV}$ in multicellular eggs.

If resting potential were the result of charge separation by an intact lipid layer, it should be abolished when the lipid layer is punctured or permeabilized. However, when the worm exited the shell into the suction pipette during the measurement, the suction pulled the shell/lipid layer around the measuring electrode and a more positive, but stable potential of -40 to $-51 \mathrm{mV}$ remained in four measurements. This suggests that charges in the shell itself are responsible for a large portion of the potential. The application of $15 \mathrm{mM} \mathrm{ZnSO}_{4}$ caused $+52 \pm 4 \mathrm{mV}$ depolarization in $30 \mathrm{~min}$, about $75 \%$ of the depolarization measured in mature intact eggs.

We expected that microwaving eggs just to boiling would permeabilize their lipid membranes and result in red-dyed eggs that had little or no resting potential. However, after staining overnight in acid fuchsin dye and rinsing twice, microwaved eggs were either permanently stained dark red or they were a light red color and cleared rapidly when they were removed from the pink rinse $\mathrm{H}_{2} \mathrm{O}$ and placed in the fresh $\mathrm{H}_{2} \mathrm{O}$ of the measuring chamber. By the end of the measurement, eggs that cleared rapidly were indistinguishable from eggs that were never placed in acid

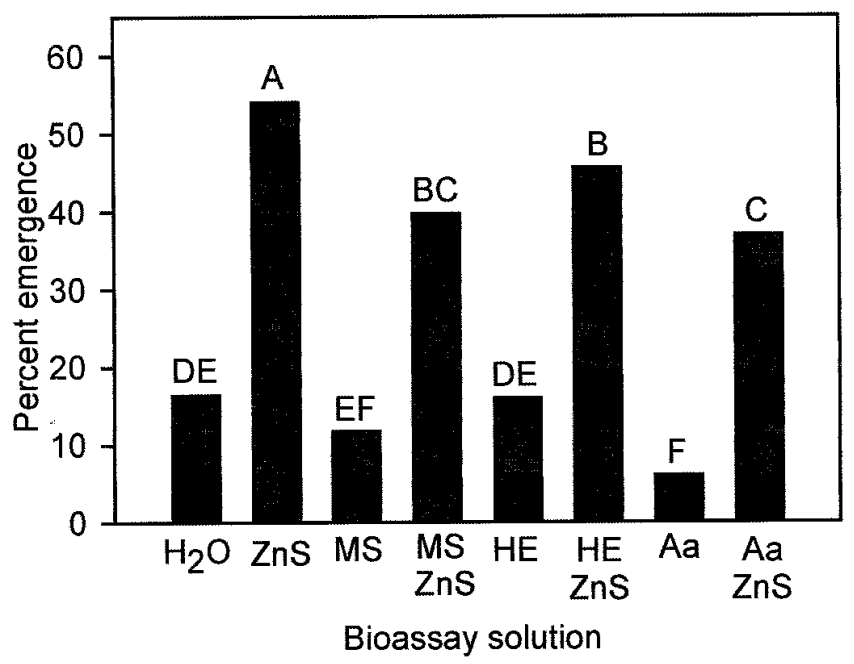

Fig. 6. Percent emergence after treatments with $N$-2-hydroxyethylpiperazine$N^{\prime}$-2-ethanesulfonic acid (HEPES [HE]), 2-( $N$-morpholino)ethanesulfonic acid (MES [MS]), or $\mathrm{ZnSO}_{4}(\mathrm{ZnS})$ solutions at a final concentration of $15 \mathrm{mM}, 2$-hydroxymethylenecyclopentanone (Aa) at a final concentration of $100 \mathrm{ppm}$, combinations of solutions, or $\mathrm{H}_{2} \mathrm{O}$. Bars are means of five repetitions. Different letters above the bars denote significant differences $(P=$ $0.0001)$. These differences were significant in two of three repetitions; exceptions are described in text. fuchsin, suggesting that the dye had not penetrated the shell but had only adhered to the surface. Correspondingly, in measurements of eggs that cleared, initial potentials before treatment and depolarizations after addition of $15 \mathrm{mM} \mathrm{ZnSO}_{4}$ (Table 3) were similar to those of mature eggs that were not microwaved (Table 1).

Permanently dyed eggs contained nematodes that appeared cracked or blistered and were likely dead; they were observed frequently in microwaved samples, approximately 50 to $100 \%$, versus only approximately 2 to $3 \%$ in nonmicrowaved samples of eggs stained overnight. Although the lipid layer was permeable in these eggs, potential was measurable, again suggesting accumulation of charge in the shell. In these permanently red eggs, the potentials before treatment were less negative and the depolarizations after $15 \mathrm{mM} \mathrm{ZnSO}$ were much less positive than in eggs that rapidly cleared (Table 3 ).

Thirty minutes after addition of $\mathrm{ZnSO}_{4}$, potentials of empty egg shells and both clearing and permanently dyed eggs were similar. With one exception, they fell in the range of +3 to $+15 \mathrm{mV}$. Thus, the different average depolarizations resulted mainly from initial differences in resting potential.

\section{DISCUSSION}

Little is known about the process that $H$. glycines uses to discern when a host plant is present and environmental conditions are favorable for hatching. Likewise, little is known about the structure and function of the inner egg shell phospholipid membrane, which is considered the main permeability barrier of the egg shell. Although structural and permeability changes in egg shells have been associated with activation of $G$. rostochiensis $\mathrm{J} 2$ emergence (7), it is unclear if these changes involve transduction of a hatching signal. We explored the possibilities that (i) changes in the egg shell/lipid layer electrical potential or $\mathrm{pH}$ change communicate external hatching conditions to the $H$. glycines $\mathrm{J} 2$ within the mature egg, and (ii) electrophysiology could be used to screen potential use of chemicals as emergence stimulators or inhibitors.

Electrophysiology. We demonstrated that the nematode egg shell/lipid layer has a negative resting potential, most likely resulting from a combination of internal negative charges in the interior lipid layer, the perivitelline fluid surrounding the nematode, and possibly, the nematode itself. The changes in potential during impalement suggested progressive penetration; however, we cannot say with certainty which layers contributed to the resting potential and to changes in resting potential following ion addition because we could not determine the exact location of the tip of the electrode.

Resting potentials depolarized, i.e., became more positive, when ions, buffers, or inhibitors of emergence were applied. The split-chamber measurements demonstrated that the depolarization was an actual change in potential across the egg shell and lipid

TABLE 3. Staining, appearance, resting potential range, and depolarization of mature Heterodera glycines eggs 30 min after addition of $\mathrm{ZnSO}_{4}, 15 \mathrm{mM}$ final concentration

\begin{tabular}{lcccc}
\hline & \multicolumn{4}{c}{ Egg characteristics } \\
\cline { 2 - 5 } Treatment & Staining $^{\mathrm{a}}$ & Appearance & $\begin{array}{c}\text { Resting } \\
\text { potential }(\mathrm{mV})\end{array}$ & $\Delta \mathrm{E}_{\mathrm{m}}(\mathrm{mV})^{\mathrm{b}}$ \\
\hline +Microwave $^{\mathrm{c}}$ & $\begin{array}{c}\text { Permanently red } \\
\text { Clearing }\end{array}$ & $\begin{array}{c}\text { Damaged } \\
\text { Healthy }\end{array}$ & -21 to -35 & $+40 \pm 8$ \\
-Microwave & Permanently red -79 & $+76 \pm 10$ \\
& Clearing & Damaged & -4 to -32 & $+32 \pm 15$ \\
& Healthy & -51 to -63 & $+73 \pm 9$ \\
\hline
\end{tabular}

$\bar{a}$ All eggs were stained overnight in acid fuchsin egg stain and rinsed twice in $\mathrm{H}_{2} \mathrm{O}$ prior to electrophysiological measurement.

${ }^{\mathrm{b}}$ Means of three $\Delta \mathrm{E}_{\mathrm{m}} \pm \mathrm{SD}$.

${ }^{c}$ After eggs were placed in acid fuchsin egg stain, half were microwaved just to boiling. 
layer, not simply an offset caused by a changed liquid junction potential of the reference electrode when $15 \mathrm{mM}$ ion solutions were added to $\mathrm{H}_{2} \mathrm{O}$. Typically, the bath solution contains $\mathrm{Cl}^{-}$to prevent such an offset (26). We used water as the bathing medium because (i) zinc precipitated when millimolar zinc solutions were added to artificial tap water (10) or other neutral or basic buffered solutions, (ii) water has been generally used in hatching experiments, and (iii) emergence was decreased in preliminary experiments using an electrophysiological bath solution, $\mathrm{pH} 5.7$, that mimics the ion concentrations of the plant apoplast (11).

The magnitude of resting potentials discriminated between shell/lipid layers that were dye-impermeable, dye-permeable, or punctured by nematode emergence but apparently sealed around the electrode. Resting potentials of eggs that excluded dye were most negative and those of dye-permeable eggs were least negative. Intermediate values were measured in newly exited empty egg shells. These results suggest that an intact lipid layer is required for charge separation, maximum potential, and full depolarization, but that the shell itself accumulated charge.

Changes in electrical potential did not distinguish between chemical compounds that had differing effects on emergence. Neither the magnitude nor the pattern of depolarization clearly discriminated between an emergence inducer $\left(\mathrm{ZnSO}_{4}\right)$, the emergence inhibitor $(\mathrm{Aa})$, and an ion solution that did not affect emergence $\left(\mathrm{CaCl}_{2}\right)$. Furthermore, when $\mathrm{ZnSO}_{4}$ was applied, neither the magnitude nor the pattern of depolarization distinguished between mature eggs that could emerge and immature eggs that could not. Although emergence was not correlated with depolarization, we cannot completely exclude the possibility that electrical potential change plays a role in hatching. We probably measured the total potential difference between the exterior and interior egg shell/ lipid layer. What may be more relevant, and more difficult to measure, is the potential difference between the perivitelline fluid and $\mathrm{J} 2$ cells, and the interactions of ions with the shell apart from interactions with the lipid layer.

Changes in surface charge, charges moving across a membrane, and internal metabolic changes all can contribute to measured changes in electrical potential. Our results suggest that changes in surface charge caused the nematode egg depolarization. Although $\mathrm{Cl}^{-}$apparently penetrated the egg shell/lipid layer, this movement of charge did not contribute to depolarization because a corre-

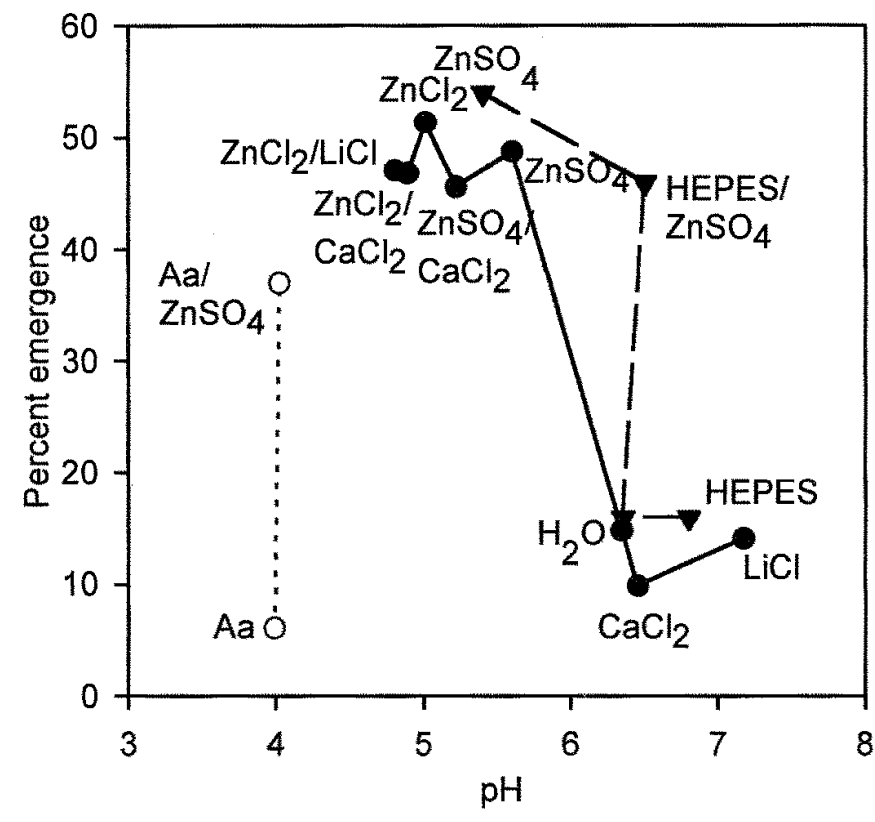

Fig. 7. Percent emergence as a function of $\mathrm{pH}$. Percent emergence shown in Figures 4 (solid line) and 6 (dashed and dotted lines) and $\mathrm{pH}$ values provided in the text were plotted as pairs. sponding potential change with opposite polarity occurred at the reference electrode. The results instead suggest that the egg shell accumulated positive charges following ion addition: (i) divalent cations caused greater depolarization than monovalent; (ii) concentration dependence was seen with monovalent ions between 5 and $15 \mathrm{mM}$, but divalent ions had already reached maximum values at $5 \mathrm{mM}$; (iii) potentials repolarized to a much greater extent after $\mathrm{LiCl}$ addition than after $\mathrm{ZnSO}_{4}$ or $\mathrm{ZnCl}_{2}$ addition; (iv) buffers containing millimolar $\mathrm{K}^{+}$caused depolarization; (v) protons caused depolarization; and (vi) resting potentials and depolarization from ion addition were measured in empty shells.

Consistent with our results, Clarke and Perry (7) reported that $\mathrm{Zn}^{2+}$ bound to the $G$. rostochiensis egg shell, displaced two-thirds of the bound $\mathrm{Ca}^{2+}$, and accumulated in excess of the original $\mathrm{Ca}^{2+}$ concentration when measured by X-ray microanalysis. However, in their experiments, added $\mathrm{Ca}^{2+}$ did not bind to the shell and $\mathrm{Mg}^{2+}$ had little effect on egg shell $\mathrm{Ca}^{2+}$, whereas in our experiments, $\mathrm{Ca}^{2+}$ and $\mathrm{Mg}^{2+}$ both caused large depolarizations. Clark and Perry (7) suggested that egg shells have three types of cation binding sites: one type in the outer egg shell, a second in the lipoprotein layer, and a third in the lipoprotein layer that becomes accessible when egg shells are treated with hatching agents. If $\mathrm{Cl}^{-}$entered the egg and excess cation remained in solution, free positive charges would be attracted to the vicinity of the egg surface without binding. Under these conditions, positive charges within the shell could also be redistributed, but amounts of bound $\mathrm{Ca}^{2+}$ would not be changed.

The unexpected observation that the egg shell/lipid layer was freely permeable to $\mathrm{Cl}^{-}$may have practical application. If confirmed with labeled $\mathrm{Cl}^{-}$experiments, it is possible that other small anions that are toxic to the nematode could cross the lipid barrier. Anion movement into the egg may require an acidic environment or an accompanying divalent cation.

pH. Emergence caused by ion addition was more related to solution $\mathrm{pH}$ than to depolarization. This relationship can be seen more clearly by pairing the average $\mathrm{pH}$ of each ion and combination solution with the percentages of emergence from Figure 4 (Fig. 7, solid line). Emergence caused by single ions formed a curve that was similar to the right half of the $\mathrm{pH} /$ hatching curve shown in Tefft and Bone's study of the effect of zinc on hatching (27). Our optimum for $\mathrm{ZnCl}_{2}$, $\mathrm{pH} 5.0$, was only slightly lower than the 5.3 that they reported. When zinc was added to calcium and lithium solutions, the solution $\mathrm{pH}$ became more acidic and emergence increased as they reported. Zinc has a dominant effect on $\mathrm{pH}$ both singly and in combination because the cations $\mathrm{Ca}^{2+}$ and $\mathrm{Li}^{+}$and the anions $\mathrm{Cl}^{-}$and $\mathrm{SO}_{4}{ }^{2-}$ are relatively neutral, whereas $\mathrm{Zn}^{2+}$ is a strong Lewis acid, and the $\mathrm{ZnCl}_{2}$ solution contained added $\mathrm{HCl}$.

However, when HEPES and Aa emergence data (Fig. 6) were added to the plot (Fig. 7, dotted and dashed lines), it became apparent that the effect of $\mathrm{Zn}^{2+}$ addition on emergence was independent of solution $\mathrm{pH}$. Zinc was an effective emergence stimulator between $\mathrm{pH} 4$ and 6.6. Furthermore, change in $\mathrm{pH}$ did not account for increased emergence when $\mathrm{Zn}^{2+}$ was added to HEPES or Aa (Fig. 7). The greatly increased emergence resulting from $\mathrm{Zn}^{2+}$ plus buffer approached that caused by $\mathrm{ZnSO}_{4}$ itself, a very surprising result considering that zinc solubility decreases 100 -fold with each $\mathrm{pH}$ unit increase (15). Thus, in $\mathrm{Zn}^{2+}$ plus buffer experiments, the effective $\mathrm{Zn}^{2+}$ concentration was approximately $150 \mu \mathrm{M}$ after precipitate formed. $\mathrm{ZnSO}_{4}$ may stimulate emergence at concentrations as low as $2 \mathrm{mM}$, and $15 \mathrm{mM}$ was midrange for

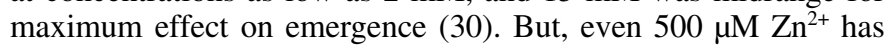
been reported to be no more effective in stimulating emergence than $\mathrm{H}_{2} \mathrm{O}(27,30)$. Possibly the precipitated $\mathrm{Zn}^{2+}$ played a role in emergence in these buffered experiments.

Although $\mathrm{Zn}^{2+}$ consistently stimulates emergence in laboratory experiments $(5,8,27,30)$, thus far $\mathrm{Zn}^{2+}$ application has not been of practical use in managing the life cycle of $H$. glycines in the field. 
When zinc fertilizers were applied to soil, hatching was unaffected (5). The authors suggested that free $\mathrm{Zn}^{2+}$ was not available in clay soil as predicted by Clarke and Shepherd (8), or perhaps that the soil was too alkaline. Nonetheless, considering our results that $\mathrm{ZnSO}_{4}$ overcame the emergence inhibition caused by Aa and that the two appeared to compete in depolarization, the interaction of zinc fertilizer and Aa should be tested in soil environments.

\section{ACKNOWLEDGMENTS}

Contribution from Missouri Agricultural Experiment Station Journal Series 13149. This research was supported by the Missouri Soybean Merchandizing Council and USDA Special Grant, Biology and Management of the Soybean Cyst Nematode. We thank K. Colgrove and A. Muriithi for their excellent technical assistance.

\section{LITERATURE CITED}

1. Atkinson, H. J., and Fowler, M. 1990. Changes in polyphosphoinositide metabolism in Globodera rostochiensis following stimulation to hatch by potato root diffusate. Nematologica 36:417-423.

2. Atkinson, H. J., Taylor, J. D., and Ballantyne, A. J. 1980. The uptake of calcium prior to the hatching of the second-stage juvenile of Globodera rostochiensis. Ann. Appl. Biol. 94:103-109.

3. Atkinson, H. J., Taylor, J. D., and Fowler, M. 1987. Changes in the second stage juveniles of Globodera rostochiensis prior to hatching in response to potato root diffusate. Ann. Appl. Biol. 110:105-114.

4. Barker, K. R. 1985. Nematode extraction and bioassays, vol. 2, methodology. Pages 19-35 in: An Advanced Treatise on Meloidogyne. K. R. Barker, C. C. Carter, and J. N. Sasser, eds. North Carolina State University Graphics, Raleigh, NC.

5. Behm, J. E., Tylka, G. L., Niblack, T. L., Wiebold, W. J., and Donald, P. A. 1995. Effects of zinc fertilization of corn on hatching of Heterodera glycines in soil. J. Nematol. 27:164-171.

6. Bird, A. F., and McClure, M. A. 1976. The tylenchid (Nematoda) egg shell: Structure, composition and permeability. Parasitology 72:19-28.

7. Clark, A. J., and Perry, R. N. 1985. Egg-shell calcium and the hatching of Globodera rostochiensis. Int. J. Parasitol. 15:511-516.

8. Clark, A. J., and Shepherd, A. M. 1966. Inorganic ions and the hatching of Heterodera spp. Ann. Appl. Biol. 58:497-508.

9. Dropkin, V. H. 1990. Exercise 24: Methods of aliquoting. Pages 178-180 in: Plant Nematology Laboratory Manual. B. M. Zuckerman, W. F. Mai, and L. R. Krusberg, eds. University of Massachusetts Agricultural Experiment Station, Amherst.

10. Greenaway, P. 1970. Sodium regulation in the freshwater mollusc Limnaea stagnalis (L.) (Gastropoda: Pulmonata). J. Exp. Biol. 53:147-163.

11. Higinbotham, N., Etherton, B., and Foster, R. J. 1964. Effect of external $\mathrm{K}, \mathrm{NH}_{4}, \mathrm{Na}, \mathrm{Ca}, \mathrm{Mg}$, and $\mathrm{H}$ ions on the cell transmembrane electropotential of Avena coleoptiles. Plant Physiol. 39:196-203.

12. Hille, B. 1992. Ionic Channels of Excitable Membranes. 2nd ed. Sinauer Associates, Inc., Sunderland, MA

13. Kraus, G. A., Johnston, B., Kongsjahju, A., and Tylka, G. L. 1994. Synthesis and evaluation of compounds that affect soybean cyst nematode egg hatch. J. Agric. Food Chem. 42:1839-1840.

14. Kraus, G. A., Vander Louw, S. J., Tylka, G. L., and Soh, D. H. 1996.
Synthesis and testing of compounds that inhibit soybean cyst nematode egg hatch. J. Agric. Food Chem. 44:1548-1550.

15. Lindsay, W. L. 1979. Zinc. Pages 211-219 in: Chemical Equilibria in Soils. John Wiley \& Sons, New York

16. Masamune, T., Masaki, A., Takasugi, M., and Katsui, N. 1982. Isolation of a natural hatching stimulus, glycinoeclepin A, for the soybean cyst nematode. Nature 297:495-496.

17. Niblack, T. L., Heinz, R. D., Smith, G. S., and Donald, P. A. 1993. Distribution, density, and diversity of Heterodera glycines in Missouri. J. Nematol. 25(suppl.):880-886.

18. Perry, R. N. 2001. Analysis of the sensory responses of parasitic nematodes using electrophysiology. Int. J. Parasitol. 31:909-918.

19. Perry, R. N., and Trett, M. W. 1986. Ultrastructure of the eggshell of Heterodera schachtii and $H$. glycines (Nematoda: Tylenchida). Rev. Nematol. 9:399-403.

20. Perry, R. N., Wharton, D. A., and Clarke, A. J. 1982. The structure of the egg-shell of Globodera rostochiensis (Nematoda: Tylenchida). Int. J. Parasitol. 12:481-485.

21. Riga, E., Holdsworth, D. R., Perry, R. N., Barrett, J., and Johnston, M. R. L. 1997. Electrophysiological analysis of the response of males of the potato cyst nematode, Globodera rostochiensis, to fractions of their homospecific sex pheromone. Parasitology 115:311-316.

22. Riga, E., Perry, R. N., and Barrett, J. 1996. Electrophysiological analysis of the response of males of Globodera rostochiensis and G. pallida to their female sex pheromones and to potato root diffusate. Nematologica 42:493-498

23. Riga, E., Perry, R. N., Barrett, J., and Johnston, M. R. L. 1996. Electrophysiological responses of males of the potato cyst nematodes, Globodera rostochiensis and G. pallida, to their sex pheromones. Parasitology 112:239-246.

24. Rolfe, R. N., Barrett, J., and Perry, R. N. 2000. Analysis of chemosensory responses of second stage juveniles of Globodera rostochiensis using electrophysiological techniques. Nematology 2:523-533.

25. Rona, J. P., Cornel, D., and Heller, R. 1977. Direct measurement of the potential difference between the cytoplasm of free cells of Acer pseudoplatanus L. and the external medium. Bioelectrochem. Bioenerg. 4:185194.

26. Sherman-Gold, R., ed. 1993. Axon Guide for Electrophysiology and Biophysics Laboratory Techniques. Axon Instruments, Inc., Foster City, CA.

27. Tefft, P. M., and Bone, L. W. 1984. Zinc-mediated hatching of eggs of soybean cyst nematode, Heterodera glycines. J. Chem. Ecol. 10:361372.

28. Thompson, J. M., and Tylka, G. L. 1997. Differences in hatching of Heterodera glycines egg-mass and encysted eggs in vitro. J. Nematol. 29:315-321.

29. Tsutsumi, M., and Sakurai, K. 1966. Influence of root diffusates of several host and nonhost plants on the hatching of the soybean cyst nematode, Heterodera glycines Ichinohe. Jpn. J. Appl. Entomol. Zool. 10:129-137.

30. Walk, T. 1996. Investigations of hatching of Heterodera glycines. M.S. thesis. University of Missouri, Columbia.

31. Wharton, D. A., Rolfe, R. N., and Perry, R. N. 2000. Electrophysiological activity during recovery from anhydrobiosis in fourth stage juveniles of Ditylenchus dipsaci. Nematology 2:881-886.

32. Yen, J. H., Niblack, T. L., and Wiebold, W. J. 1995. Dormancy of Heterodera glycines in Missouri. J. Nematol. 27:153-163. 